\title{
LA TRAYECTORIA POLÍTICA DEL CARDENAL GIULIO ALBERONI (1708-1720)
}

\author{
Rosa Ma Alabrús IGLESIAS \\ Universitat Abat Oliba CEU
}

Fecha de recepción: enero de 2010

Fecha de aceptación: octubre de 2010

El cardenal Giulio Alberoni fue un personaje controvertido especialmente después de la Guerra de Sucesión española por su escalada fulgurante como consejero de Isabel Farnesio, sobrina del duque de Parma. Este estudio trata de analizar sus orígenes, el porqué de su adscripción a la causa borbónica durante el conflicto bélico y las estrategias que mantuvo con la Santa Sede tras el mismo.

Alberoni nació en 1664 en Piacenza en el seno de una familia humilde. Su padre era un jardinero al servicio del duque de Parma. De pequeño ejerció de monaguillo llegando a ser campanero y, con los años, presbítero de su ciudad ${ }^{1}$. Su inteligencia propició que Monseñor Barni lo tuviera entre sus clérigos preferidos pues destacaba, brillantemente, en sus estudios en la congregación de clérigos regulares de San Pablo (o padres Barnabitas). También el duque de Parma lo protegió por su talento y lo presentó a Luis José de Borbón, duque de Vendôme, que fue a socorrer Cremona y la Lombardía, en nombre de Luis XIV, cuando estas fueron invadidas por los imperiales en 1706. Alberoni no tardó en congeniar con aquél pues dominaba perfectamente el francés ${ }^{2}$. La primera misión del joven Alberoni fue la de difundir las ventajas de la adscripción a Francia en lugar de adherirse al Emperador en Italia, pues el duque de

1. Biblioteca Nacional (BNM). Ms. 10927. Nacimiento del cardenal Julio Alberoni y compendio de su vida, tomo 42, pp. 1-4.

2. Real Academia de la Historia (RAH). Fondo Ángel Ferrari. Rousset, J.: Histoire du Cardinal Alberoni et de son ministère jusqu'à à la fin de l'année 1719, La Haya, 1720, p. 57. Según F. de Castellví este libro fue escrito por Jean Rousset de Missy. De hecho en la portada del libro figuran las iniciales J. R.; CAStellví, F. de: Narraciones históricas, Madrid, 1999, volumen III, p. 116; PÉREz SAMPER, M. A.: Isabel de Farnesio, Barcelona, 2003, p. 123. 
Parma rechazaba frontalmente el imperialismo de los Habsburgo. Tras la llegada del duque de Orleáns como enviado a Italia de Luis XIV, Vendôme y Alberoni obtuvieron el encargo de ir a Flandes y realizar allí la misma operación, promoviendo la conveniencia de posicionarse al lado de los franceses. Al poco pasaron a París, donde el rey de Francia en persona quiso felicitar a Alberoni por sus habilidades manifestadas con los flamencos. No tardó en otorgarles, tanto a su protector como al joven clérigo, un nuevo proyecto: el de viajar a España para frenar la euforia austracista desatada en Barcelona, tras la expulsión de 9000 borbónicos y la derrota sufrida por Felipe V al intentar reconquistar la ciudad en manos de los aliados (1706). Al mismo tiempo, el hecho que el Archiduque Carlos hubiese celebrado Cortes en la capital catalana y dirigiese una expedición hacia Castilla para tomar Madrid y proclamarse rey de España e Indias, fue decisiva para que el monarca francés enviara cuanto antes a sus dos agentes en suelo español ${ }^{3}$.

En los territorios italianos la división fue una constante a lo largo de la guerra. Víctor Amadeo II, duque de Saboya y padre de la primera esposa de Felipe V, inicialmente, en 1702, permaneció a favor de Francia cuando los austriacos y alemanes ocuparon el Milanesado, pero en 1703, ante la ocupación de Luis XIV de este ducado, se pasó sin dudarlo al otro bando. El duque de Parma y Piacenza, Francisco Farnesio, tío de la segunda esposa de Felipe V (Isabel), desde el momento en que el príncipe Eugenio de Saboya ocupó sus dominios (1706-08) manifestó simpatías por el Borbón y buscó la ayuda del duque de Vendôme para promover la unidad italiana ante el creciente poderío del emperador Leopoldo en el Mediterráneo. Por aquél entonces el papa Clemente XI predicaba la neutralidad en Italia.

Sería interesante subrayar algunas de las razones por las que la Santa Sede acabó posicionándose a favor de Carlos de Austria a partir de 1709. Una de ellas fue la actuación de Melchor Rafael de Macanaz y el equipo de gobierno profrancés de Felipe V en España ( $\mathrm{M}^{\mathrm{a}}$ Anne de la Trémoille, más conocida como la princesa de los Ursinos, muy próxima a la reina $\mathrm{M}^{\mathrm{a}}$ Luisa Gabriela de Saboya para la que desempeñó funciones como secretaria personal, Jean Orry, Amelot...) en la fiscalización del clero a partir de 1706. Los argumentos esgrimidos por éstos fueron las necesidades de la guerra y una creciente ansia regalista. Pronto las quejas del arzobispo Antonio Folch de Cardona o las del prelado de Cartagena Luis Belluga no tardaron en llegar a oídos del papa lo que hizo variar la postura inicial de Roma, a la vez que poco a poco, personajes vinculados a Clemente XI, como el cardenal Francesco Acquaviva, se mostraron recelosos de las actuaciones imperiales en Italia ${ }^{4}$.

3. Biblioteca de Cataluña (BC). Ms 1553. Compendio de la vida del señor Julio Alberoni, arzobispo electo de Sevilla, primer ministro de España y cardenal, pp. 83-85.

4. Professione, A: Il ministero in Spagna e il processo del cardinale Giulio Alberoni, Turín, 1897; Bourgeols, E: Lettres intimes de J. M. Alberoni adréssées au comte Rocca, ministre des finances du Duc de Parma, Paris, 1892; Barrantes, V.: «Lettres intimes de J.M. Alberoni, adressées au comte Rocca et publiés d'après le manuscrit du collège de S. Lazaro Alberoni par E. Bourgeois», Boletín de la Real Academia de la Historia, tomo 34, cuaderno III, marzo, Madrid, 1899, pp. 192-194. No es sorprendente 
Al principio, Felipe V recibió a la pareja Vendôme-Alberoni con los brazos abiertos. Les encomendó la dirección del ejército borbónico para reconquistar Madrid, en especial en 1710, tras el segundo intento de retomar la capital por el Archiduque. Cuando en 1711 el duque de Vendôme consiguió las victorias de Villaviciosa y Brihuega contra los jefes aliados Starhemberg y Stanhope, ganó aún más prestigio en la corte de del nieto de Luis XIV. Respaldado por su fiel Alberoni, ambos realizaron la ardua labor de negociar con los aragoneses después de la pérdida de sus fueros chocando con los planes regalistas de Macanaz que, tras las críticas recibidas en Valencia, había sido trasladado a Aragón en calidad de administrador en la Junta del Real Erario de aquel reino ${ }^{5}$. Además Vendôme y Alberoni participaron en las prenegociaciones de Utrecht (1711), entre la reina Ana de Inglaterra y Luis XIV de Francia, lo que acrecentó el prestigio diplomático de ambos, a nivel internacional, con el consiguiente recelo del sector Ursinos.

En 1712, la muerte del delfín de Francia, Luis, duque de Borgoña, generó expectativas a Felipe $\mathrm{V}$ en el trono francés. El rey tuvo varias conversaciones con el duque y el abate italiano, paralelas a los preacuerdos de Utrecht. Según Castellví: «El Consejo de Estado se juntó muchas veces sobre esta novedad, y las deliberaciones se ocultaron, como también las conferencias entre el rey, reina, duque de Vendôme y el marqués de Bonac». El impasse provocado por la muerte del delfín dio de nuevo un protagonismo indiscutible a Vendôme y a su protegido que transmitieron a Felipe V los deseos contrarios de su abuelo respecto a sus pretensiones, pero aquél se negó a aceptar sus sugerencias. Sus rabietas obligaron a Vendôme y Alberoni a armarse de paciencia y a ir, a menudo, a palacio para desaconsejarle de volver a Francia como sucesor de Luis XIV. Sin embargo, en la corte, circuló el rumor de que el monarca abandonaría España. De hecho, a lo largo de la guerra, esta noticia se había difundido ya varias veces (en 1702 cuando el rey se fue a Nápoles, en 1706 tras su huída a Perpignan...) ${ }^{6}$.

Las prenegociaciones de Utrecht demostraron que Luis XIV había perdido la confianza con la Ursinos. En cambio la depositó con sus preferidos, Vendôme y Alberoni. Para nada contempló las pretensiones de la princesa sobre el ducado de Flandes tal y como ella solicitaba. La muerte de Vendôme (junio 1712), en extrañas circunstancias (algunos dan por hecho que la ingestión, en una cena en Vinaroz, de pescado en mal estado, fue la causa de la muerte del duque; otros apuntan a un asesinato), alimentó todo tipo de especulaciones. Solo entonces Felipe V se apresuró a desmentir que fuera a abandonar el trono. El monarca español no tardó en difundir un comunicado, al mes siguiente, para apaciguar las críticas vertidas contra él, de su propio bando, contrarias a sus deseos?

que el interés de la historiografía italiana por Alberoni se acentúe a finales del siglo XIX en el marco de la euforia del Risorgimento italiano que busca en Alberoni uno de sus antecedentes.

5. GiMÉnEZ LópeZ, E: Los servidores del rey en la Valencia del siglo XVIII. Valencia, 2006, pp. 17 y 65.

6. Castellví, F. de: Narraciones..., volumen III, pp. 414-415 y p. 480; BaCAllar, V. (marqués de San Felipe): Comentarios... p. 230; RAH. Rousset, J.: Histoire du Cardinal Alberoni et son ministère... pp. 59-77.

7. Castellví, F. de: Narraciones..., volumen III, pp. 486-87 y 88. 
Alberoni, irremediablemente solo en Madrid, siguió ejerciendo como representante diplomático de Luis XIV, pero las hostilidades detectadas hacia su persona, además de tener en contra a Felipe $\mathrm{V}$, ahora, por haberle recomendado la renuncia al trono francés en Utrecht, eran tantas (el secretario del rey, Grimaldo, lideraba a los grandes de España y no veía bien su papel en la corte; la Ursinos le tenía celos pues consideró que Utrecht le había dado prestigio y credibilidad política internacional y le había quitado a ella, en cambio, la «línea directa» con Versalles) que, de nuevo, solicitó entrevistarse con el rey de Francia, como en 1706.

La muerte de $\mathrm{M}^{\mathrm{a}}$ Luisa Gabriela de Saboya (14 de febrero de 1714) afectó emocionalmente mucho a Felipe V. Dejó los asuntos de gobierno en manos de José Grimaldo (secretario de despacho), del cardenal Franceso de Giudice (consejero e inquisidor general) y de $\mathrm{M}^{\mathrm{a}}$ Anne de la Trémoille (se convirtió ahora en su asesora personal). Ésta última adelantándose a un posible cuestionamiento de su papel en la corte, tras el fallecimiento de la reina, aprovechó la debilidad del monarca, para destituir al presidente del Consejo de Castilla, Francisco Ronquillo, por negarse a acatar las reformas institucionales, con secretarías a la francesa, que ella y Orry proponían y que a $\mathrm{M}^{\mathrm{a}}$ Luisa sí le hubieran agradado.

Tanto cambio forzado originó numerosas quejas de Grimaldo, Ronquillo y, en general, de la nobleza castellana. El embajador de Luis XIV, el marqués de Brancás, las transmitió al rey de Francia que no tardó en exigir una explicación a la Ursinos. Ésta creyó matar dos pájaros de un tiro si enviaba a la corte de Versalles al cardenal de Giudice para desmentir las informaciones del embajador. Al mismo tiempo era conocedora de los celos del cardenal hacia Alberoni, por la escalada del segundo a partir de Utrecht. Pensó que de Giudice no dudaría en aceptar el cargo y ella misma le hizo ver cómo podría promocionarse ante Luis XIV. De ese modo, una vez liberada del inquisidor general, podría ejercer el poder de forma despótica o tirana ${ }^{8}$. Fue en ese momento que Macanaz se reafirmó en sus planteamientos regalistas. Tras el ruido provocado con su conocido Pedimento (1713) inspirado en el Discurso sobre los abusos de la corte de Roma del obispo antiromanista Solís de Lérida (1709), escribió en agosto de 1714 la Respuesta del Fiscal exigiendo el derecho a las regalías de la Corona. El hecho irritó tanto al Consejo de Castilla y a los obispos L. Belluga y F. de Giudice que lo denunciaron a la Santa Sede?

Alberoni y el duque de Parma, por su parte, plantearon el tema al cardenal Francesco Acquaviva -embajador de Felipe V en Roma-. Al final, consiguieron que Felipe dejara el regalismo en segundo plano y que se diera cuenta de la conveniencia

8. BNM. Ms. 12173. BACAllar, V.: Comentarios .... folios 31, 35-37, 41, 57-60; RAH. RousSET, J.: Histoire du Cardinal Alberoni et son ministère..., pp 77-81. Si Rousset habla de la Ursinos como una despótica, Bacallar realiza afirmaciones parecidas (tirana) y añade la ineptitud del marqués de Villena, al que la princesa nombró como condestable del rey; CASTELlví, F. de: Narraciones históricas, Madrid, 2002, volumen IV, p. 23.

9. VilAR, J. B.: El cardenal Luis Belluga. Granada, 2a ed., 2005, pp. 30-191; IRIGOYEN LóPEZ, A.: Un obispo, una diócesis, un clero: L. Belluga, prelado de Cartagena. Murcia, 2005, pp. 137-147. 
de un nuevo matrimonio con una italiana, en concreto la sobrina del duque de Parma, Isabel de Farnesio, para ayudar a limar asperezas con el santo padre y con los territorios italianos ${ }^{10}$. Durante el verano de 1714, Alberoni se desplazó a Parma (convirtiéndose en un triple agente - de Luis XIV, del duque de Parma y del pontífice-) para dar instrucciones concretas a Isabel como futura esposa de Felipe V. Las recomendaciones que Alberoni dio a la futura reina de España fueron las de, por una parte, desembarazarse de la consejera real y, por otra, llevarlo consigo, en calidad de secretario personal, para que pudiera ganar poco a poco la confianza del monarca e informar puntualmente al duque de Parma y a la Santa Sede de todo lo que ocurría en la corte.

Al tío de Isabel, Francisco Farnesio, le interesaba esta alianza puesto que su deseo fue siempre el de evitar una excesiva dependencia en Italia del Imperio y apostar por un equilibrio en el Mediterráneo. La inquietud del duque de Farnesio venía desde que José I ocupó los territorios de Parma y Piacenza (1706-08) considerándolos feudatarios de los Habsburgo. Al no tener hijos propios, el matrimonio de su sobrina con Felipe V en 1714 suponía una oportunidad para él de recobrar su reputación y ganar tiempo para asegurar herederos. Por otro lado, al papa le interesaba controlar las pretensiones fiscalizadoras de Felipe $\mathrm{V}$ hacia el clero. En un momento tan delicado en que el jansenismo y el regalismo coincidían en muchos aspectos, Francesco Acquaviva y el jesuita Guillermo Daubenton (éste último autor, desde 1703, de una campaña contra el jansenismo y colaborador en la redacción papal de la Bula Unigenitus en 1713 contra los postulados regalistas) contribuyeron al cese de Macanaz y a la sustitución del confesor del rey, el jesuita Robinet, por el propio Daubenton en 1715, esforzándose en crear una imagen de la Iglesia romana abiertamente antiregalista ${ }^{11}$.

Macanaz sostiene que en 1714 la conexión de Giudice-Alberoni era total. El primero, durante su estancia en Francia estaba al corriente de todo gracias al segundo y éste último, predispuso a Mariana de Neoburgo (viuda de Carlos II y tía de la Farnesio), exiliada en Bayona, contra la Ursinos y él mismo. Joaquín Maldonado Macanaz, un descendiente de Macanaz, hablaba pestes de Alberoni, al que consideraba inductor, junto con la Farnesio, de un verdadero «golpe de Estado» contra su antepasado y la princesa de los Ursinos ${ }^{12}$. La complicidad Giudice-Alberoni-Acquaviva fue clave para que se abriese un proceso inquisitorial contra Macanaz, por haber defendido un modelo regalista de Iglesia y de Estado. El tribunal del Santo Oficio, a manos de la Compañía de Jesús, acusó de «mal católico» al autor del Pedimento y éste se justificó

10. RAH. Rousset, J. : Histoire du Cardinal Alberoni et son ministère ..., pp. 89-98.

11. Alabrús, R. M.: «Imagen y opinión sobre la Compañía de Jesús en la España del siglo XVIII» en Betrán, J. L. (ed.) La revolución mediática de los jesuitas en el mundo hispano, Madrid, 2010, pp. 219-250.

12. RaH. Rousset, J.: Histoire du Cardinal Alberoni et son ministère..., pp. 109-117; MALdONADO MACANAZ, J.: El cardenal Julio Alberoni, Boletín Real Academia Historia, Madrid, tomo 38, 1901, pp. 447; EGIDO, T.: «El regalismo y las relaciones Iglesia-Estado» en MESTRE, A. (dir.) Historia de la Iglesia en España, Madrid, 1979, vol. IV, pp. 142-149. 
ante Clemente XI de que el Consejo de Castilla había manipulado sus escritos para destituirle ${ }^{13}$.

En septiembre de 1714 murió Luis XIV. Nuevamente, Felipe V quiso aspirar al trono francés a pesar de las renuncias hechas en Utrecht. No le faltaron confidentes, como Macanaz, que, desde su exilio en Francia, alentaron esta posibilidad. Alberoni, al igual que lo hizo Vendôme años atrás, intentó sacar la idea de la cabeza al monarca español. Le dijo a Felipe que era mejor dejar las cosas como estaban y no enfrentarse al regente de Francia, el duque de Orléans ${ }^{14}$.

Alberoni, ya convertido en secretario y asesor de la reina después de casi un año, ejercía un creciente influjo sobre el rey quién le otorgó, progresivamente, más funciones. En Cataluña, acordó con el intendente José Patiño la disolución de las instituciones catalanas después de la derrota del 11 de septiembre de 1714, la formación de una Real Junta de Gobierno (1715) y la consiguiente militarización del Principado ${ }^{15}$. Junto con el flamenco Bergeick mantuvieron el derecho civil catalán y articularon un diseño más posibilista de la Nueva Planta (1716), con juristas borbónicos catalanes como F. d'Ametller o J. d'Alòs, de lo que les hubiera gustado a la princesa de los Ursinos, a Macanaz, o al vizconde del Puerto. A lo largo del tiempo, éstos creyeron que el pragmatismo llevado a cabo por sus adversarios políticos había alimentado el espíritu de rebelión permanente de los catalanes desde 1714 y así lo manifestaron Macanaz y el marqués de Santa Cruz en sus escritos ${ }^{16}$. Después de la expulsión de Macanaz a Francia y del envío del vizconde del Puerto a Ceuta en 1715 ambos siguieron escribiendo textos para desacreditar la imagen de Patiño y Alberoni. El mismo Patiño, entre 1715 y 1717 tuvo que hacer frente a varios requerimientos del rey, por supuestas denuncias hacia su persona en el sentido de no haber sabido prever convenientemente las sediciones catalanas posteriores a la guerra. También circularon abundantes críticas contra Alberoni durante este tiempo ${ }^{17}$.

Los maquis austracistas se convirtieron en una obsesión tanto para Alberoni como para Patiño. Éste último, paralelamente a la represión ejercida en el Principado, hizo circular textos que desprestigiasen a los catalanes. Pensaba que erosionar la imagen de éstos podía contrarrestar el aumento de insurgentes ${ }^{18}$. Progresivamente, desconfiaron de sus propios hombres en Cataluña. Encargaron al jurista borbónico Josep d'Alós i Ferrer un informe en 1715 para saber hasta que punto en Barcelona se seguía manteniendo contacto con el gobierno de los exiliados austracistas en Viena o en los territorios italianos. Lo cierto es que Carlos VI de Austria tenía sus expectativas deposi-

13. BN. Ms. 2768, MACANAZ, M. R. de: Males, daños y perjuicios... fols. 86, 90 y 91.

14. RAH. Rousset, J.: Histoire du Cardinal Alberoni et son ministère... p.p. 123-124.

15. TORRAS I RiBÉ, J. M.: Felip V contra Catalunya, Barcelona, 2005, pp. 162-164 y 214; MOLAS, P.: Los gobernantes de la España Moderna, Madrid, 2008, pp. 236-237.

16. MerCAder i RiBA, J.: Felip Vi Catalunya. Barcelona, 1985, pp. 25-26, 31-33 y 95-96; SANPERE y MiQuel, S.: Fin de la nación catalana, Barcelona, 1905, p. 74.

17. EgIDO, T.: Sátiras políticas de la España Moderna, Madrid, 1973, pp. 210-211.

18. SANPERE y MiQuel, S.: Fin de la nación...., p. 671. 
tadas en dos frentes. Uno era el de los comerciantes católicos y judíos flamencos con los jacobitas escoceses que pretendieron proclamarle rey (1715-16) en las Indias ${ }^{19}$. El otro, era el catalán, por la presión ejercida de los exiliados austracistas en Italia. Alós acabó el informe, previendo el posible retorno de las tropas del Archiduque Carlos a Barcelona, lo que contribuyó a levantar sospechas contra su propia familia. A su hijo, Francesc d'Alós, asesor directo de la superintendencia para la aplicación del catastro en Cataluña y oidor y regente de la Audiencia de Cataluña, lo acusaron de «blando y condescendiente» con sus compatriotas, lo que «motivaba una muy notable inobservancia de sus obligaciones ${ }^{20}$. En estos años, los recelos de Patiño y Alberoni se vertieron también hacia el inquisidor general, el cardenal Francisco de Giudice. Lo acusaron, ante la reina, de mostrar al infante Luis (el hijo mayor de Felipe V y $\mathrm{M}^{\mathrm{a}}$ Luisa Gabriela de Saboya) ideas opuestas a las de su padre en relación a un presunto restablecimiento de las Constituciones catalanas y seguir manteniendo contactos con los austracistas españoles exiliados en Italia, por lo que Isabel no tardó en facturarlo a Roma en $1716^{21}$.

Alberoni, no obstante, creyó siempre que el mayor problema estaba fuera. Por ese motivo intentó, desesperadamente, buscar soluciones para incentivar una unidad italiana, recurriendo a los argumentos que en su día hiciera su protector Vendôme, para contrarrestar la proyección de los austriacos no solo en Italia sino en Cataluña impidiendo la llegada de refuerzos de aquellos territorios que pudieran fomentar la sedición contra la monarquía. Por ello Alberoni-Patiño acordaron invadir Cerdeña en 1717. A pesar de que la invasión de la isla se realizó en julio, no fue hasta mediados de agosto que fuentes diplomáticas españolas difundieron el Mundo Político y Cristiano, escrito por Grimaldo el 9 de agosto, buscando justificaciones, pues la oposición sarda, a la capitulación, fue mayor de lo esperado, dando lugar a reiteradas condenas internacionales. En el manifiesto, el secretario de Estado argumentaba que Felipe V cumplió con lo estipulado en el Tratado de Utrecht cediendo Sicilia a cambio de la evacuación de los aliados de Cataluña y Mallorca. Todo lo contrario - añadía- que el Emperador quien siguió alimentando las expectativas de los catalanes desde sus posesiones italianas para erosionar al Estado borbónico ${ }^{22}$.

19. Alabrús, R. M.: «Ripperdà: un ex austriacista dins del règim borbònic» en Miscel.lània Homenatge E. Lluch i Martín, Vilassar, vol II, 2007, pp. 287-306; Bristish Library (B.L.). CAMPBELL, J.: Memoirs of the Duke de Ripperda. Apéndice «Of the consequences of a war in America», Londres, 1744, pp. 355390; Huisman, M.: La Bélgique commerciale sous l'empereur Charles VI. La Compangnie d'Ostende. Bruselas, 1902, pp. 64-69 y 83-93.

20. Mercader I RiBA, J.: Felip Vi Catalunya, Barcelona, 1985, pp. 25-26, 31-33 y 95-96; MolAs, P.: «Las Audiencias borbónicas de la Corona de Aragón. Aportación a su estudio» en Estudis, $\mathrm{n}^{\circ}$ 5, Valencia, 1976, pp. 59-124; PÉrez SAMPER, M. A.: «La familia Alós, una dinastía catalana al servicio del Estado (s. XVIII)» en Cuadernos de Investigación Histórica, nº 6, La Rioja,1982, pp. 195-239.

21. BN, MSS. 2768. MACANAZ, M. R. de: Males, daños y perjuicios...fols. 91-97 y 99-109.

22. MASsuet, P.: Historia del Duque de Riperdá, primer ministro de España, en el reinado del Sr. Felipe Quinto. Prólogo de S. J. Mañer, Madrid, 1796, pp. 33-37. En 1740, S. J. Mañer, un ex publicista austracista, tradujo con el pseudónimo de Mr. Le Margne la obra de Massuet (Vida del duque de Riperdá, traducida del francés al castellano por Mr. Le Margne, Madrid, 1740). Paralelamente el traductor hizo 
En la ocupación de Cerdeña influyeron, qué duda cabe, otros muchos motivos como los deseos del duque de Parma y su sobrina que no soportaban el hecho de que Parma fuese feudataria del Imperio. En el Tratado de Utrecht (1713), Francisco Farnesio tuvo que ratificar tal situación ante Carlos VI por falta de hijos. Cuatro años después la situación era bien distinta. El tío de Isabel pretendía que los sucesores a los ducados de Toscana, Parma y Piacenza fuesen los hijos de la reina de España, en especial el mayor, el infante Carlos $^{23}$.

Asimismo en la toma de Cerdeña de 1717 contó una cuestión de imagen y reputacionismo reivindicada por la nobleza española, puesto que, desde el final de la Guerra de Sucesión, buena parte de los grandes de España reprochaban a Felipe su fijación por Cataluña y en cómo se había gastado tanto dinero y hombres para conseguir rendirla desatendiendo Nápoles y Sicilia (que pasaron al emperador y al rey de Saboya) y Gibraltar y Menorca (a manos de los ingleses). Por esta razón los grandes aprobaron la decisión de Alberoni ${ }^{24}$.

La reacción de los imperiales no se hizo esperar. Inculparon a la corte española de haber instigado la revuelta de los turcos contra Carlos VI, a través de su emisario el príncipe de Cellamare, para que, una vez desplazado el ejército del emperador en el frente otomano, las tropas hispanas pudiesen atacar Cerdeña a su antojo. En ese sentido, el conde de Gallas, en nombre de la corte austriaca, increpó al secretario Alberoni, reiteradas veces, ante la Curia romana ${ }^{25}$.

El cardenal Acquaviva informó a Alberoni de las acusaciones formuladas contra él por los austriacos ante el Papa y le mostró la carta injuriosa de Gallas comentándole que la consideraba una infamia contra Felipe V. Por otro lado, Clemente XI se sentía amenazado por Carlos VI y tenía la sensación de que las exigencias del emperador eran cada vez mayores por lo que, de momento, siguió apoyando las estrategias de Alberoni-Parma en relación al pretendido equilibrio de poderes en el Mediterráneo. Recordemos que, tan solo un mes antes de la invasión de Cerdeña, Alberoni había recibido de aquél el capelo cardenalicio ${ }^{26}$. También el príncipe de Cellamare, emba-

otra versión, con un prólogo y bastantes añadidos, con la precisión «corregida de los muchos defectos que contenía», que es la que ha aquí se ha utilizado y que contiene el Manifiesto del Mundo Político y Cristiano de Grimaldo del 9 de agosto de 1717; ALABRÚs, R. M.: «La pluralidad de opciones políticas en el austracismo y en el borbonismo desde la Guerra de Sucesión española hasta la Paz de Viena». Revista Studi e Ricerche, Dipartimento di Studi Storici, Università degli Studi di Cagliari (en prensa); MUÑOZ GOnZÁlez, A. \& CATÁ I TuR, J. (eds.) Repressió borbònica i resistencia catalana (1714-1736), Madrid, 2005, p. 224.

23. Rah. Rousset, J.: Histoire du Cardinal Alberoni et son ministère...pp. 187-191; CASTELlví, F. de: Narraciones..., vol IV, p. 605.

24. B. L. CAmpBell, J.: Memoires of the duke... pp 42-43.

25. RaH. Rousset, J.: Histoire du Cardinal Alberoni et son ministère..., pp. 187191.

26. Rousset, J. Op. Cit., pp. 186, 191-197. 
jador de España en Paris, se justificó negando las imputaciones que le hacían los alemanes ${ }^{27}$.

Sin embargo, el papa al constatar lo que se le venía encima trató de buscar nexos de unión entre Carlos VI y Felipe V. Lejos de conseguirlo tan solo obtuvo una mayor complicidad entre el rey Jorge de Inglaterra y el regente de Francia, el duque de Orleáns. Éstos formaron una Alianza a la que no tardó en adherirse el Imperio y, posteriormente, los Estados Generales de Holanda. En toda Europa corrió la voz de que, de nuevo, la guerra volvería a reproducirse, como en 1702. Para evitarla, se convocó con celeridad a las potencias europeas en el Congreso de Londres (agosto, 1718). El monarca español envió como plenipotenciario al hombre de confianza de Alberoni, el marqués de Beretti Landi. Su misión fue convencer a la delegaciones de los países asistentes de los motivos que tenía España para invadir Cerdeña.

Finalizada la exposición, Beretti Landi dijo a los allí presentes que no temieran pues su intención no era invadir ningún territorio más. Lo único que se había pretendido era encontrar un balance of power cara a una «Italia que está al punto de su entera ruina ${ }^{28}$.

Los aliados no escucharon las explicaciones del embajador español. Se obsesionaron con que el conflicto bélico volvería a estallar de un momento a otro y centralizaron sus contrargumentaciones en que todo había pasado porque Carlos VI no había ratificado anteriormente el Tratado de Utrecht con Felipe V. No tardaron en exigir a ambos mandatarios la firma de éste. Solo así, decían, podrían reconocerse mutuamente y, a la par, el emperador renunciaría a España y las Indias y el Borbón español a Italia, Países Bajos y Francia. Valoraron las peticiones del duque de Parma, asintiendo en que Francisco tuviera a los hijos de Isabel Farnesio como sucesores. Las prisas por zanjar esta cuestión les hizo, quizá, precipitarse en la decisión de que Cerdeña pasara al rey de Saboya, Sicilia a Carlos de Austria y España se retirara de Italia ${ }^{29}$.

Alberoni, al conocer los acuerdos de Londres (1718), no los rebatió frontalmente. En la práctica, se limitó a dar largas a la aprobación de los mismos. Mientras, gestionó, con la ayuda del barón de Ripperdá, la neutralidad de los Estados Generales de Holanda durante un tiempo con promesas de que España se convertiría en su primera compradora de telas y barcos.

Macanaz, desde su exilio, dio la versión de que Felipe V consintió la invasión de Cerdeña para «tener entretenidos a los austriacos» ya que el verdadero objetivo del monarca distaba mucho de los intereses de su esposa y de su secretario, pues, de nuevo, para él, lo más importante era ser rey de Francia. Asegura que Felipe V preparó con él y con el príncipe de Cellamare una trama contra el duque de Orleáns en 1718. Días antes

27. Rousset, J. Op. Cit. pp. 197-204. Las acusaciones que Rousset dice que los imperiales formularon al Papa también son esgrimidas por F. de Castellví en sus Narraciones...vol. IV, pp. 610 y 627; Biblioteca Virtual Cervantes (BVC). BACALLAR, V.: Comentarios..., año 1718, p. 2.

28. Massuet, P.: Historia del Duque de Riperdà..., traducida por S. J. Mañer, pp. 40-45.

29. CASTEllví, F. de: Narraciones..., vol IV, pp. 626. 
del «golpe», el rey le envió una carta para que la entregase a los «Estados de Francia» y así saber hasta que punto los franceses lo apoyarían ${ }^{30}$.

Al monarca español parece que la victoria en Cerdeña no lo había ilusionado tanto como a la reina o al duque de Parma. Desde 1717, Felipe V alegó tener depresión para no asistir a los actos oficiales ni asumir responsabilidades directas en relación a la cuestión italiana. Incluso hizo un testamento preventivo a favor de una regencia compartida entre Alberoni y la reina, en el caso que no estuviese capacitado para gobernar. ¿Acaso la trama urdida por Macanaz-Cellamare en Francia lo abdujo? ¿Hasta que punto Alberoni sabía todos los detalles? P. Massuet aporta las cartas cruzadas entre Cellamare y Alberoni, durante el largo verano de 1718, fruto de las inquietudes que les creaba el estado de salud del rey. En la primera carta, Cellamare advierte a Alberoni de la necesidad de realizar la «operación» cuanto antes. En la segunda carta Cellamare pide al cardenal italiano que se decida ya, especulando, a la vez, con las consecuencias posibles derivadas de la conspiración ${ }^{31}$. Al final, Alberoni escribió al duque de Parma y a los «Estados Generales» de Francia, alegando que Felipe no estaba en condiciones, mentalmente, de asumir una regencia. Macanaz lo odió siempre por haberse echado atrás. Alberoni, con su reciente estrenado capelo cardenalicio recurrió, una vez más, a la misma estrategia pensada años atrás por Vendôme: evitar que Felipe volviera a Francia.

Tanto a Alberoni como al duque de Parma, lo que más les preocupaba era contrarrestar a Inglaterra y al Emperador. El primero parece que propuso al duque de Saboya y rey de Sicilia, una alianza con España para ocupar Nápoles. Si colaboraba a favor de un equilibrio en el Mediterráneo, Alberoni se comprometía a compensar a la Casa de Saboya con el ducado de Milán. Lo cierto es que una vez obtenido su compromiso, la armada española desembarcó en Sicilia sorprendiendo al de Saboya ${ }^{32}$. Llama la atención el gran número de soldados empleados en la conquista de Sicilia en relación a la de Cerdeña, fruto de la política de Alberoni de incrementar las arcas de la Hacienda del Estado mediante la venta de empleos y cargos militares ${ }^{33}$. El intendente general Patiño, máximo responsable del ejército, constató la poca resistencia ofrecida por los sicilianos, a diferencia de los sardos. La adscripción de ciudades como Palermo y Mesina al lado de los españoles dejó perplejos a los europeos e hizo creer a Alberoni que el resto del territorio y a continuación Nápoles, se someterían con la misma facilidad. Sin embargo Inglaterra envió «ipso facto» una flota armada a la isla y a Stanhope a negociar en Madrid. El embajador inglés propuso a la corte española lo mismo que había sostenido en el Congreso de Londres. Recordó que había que apoyar las resoluciones tomadas por los países de la Cuádruple Alianza en lo que concernía a los territorios

30. MASSUET, P.: Historia del duque de Riperdá..., traducida por S. J. Mañer, pp. 70-80.

31. Massuet, P. de: Op. cit. pp. 75-80.

32. BVC. BaCAllar, V.: (marqués de San Felipe). Comentarios..., año 1718, p. 3; RAH. Rousset, J.: Histoire du Cardinal Alberoni et son ministère... pp. 241-44.

33. Castellví, F. de: Narraciones..., vol. IV, p. 636; Andujar Castillo, F.: El sonido del dinero. Monarquía, ejército y venalidad en la España del siglo XVIII, Madrid, 2004, pp. 75-77. 
italianos y la necesidad de ratificación de las mismas tanto por parte de Carlos como de Felipe. Rotundamente se negó a restituir Gibraltar y Menorca para España. Alberoni le respondió haciendo alusiones a la memoria de Vendôme y a la necesidad de mantener el equilibrio en el Mediterráneo, por lo que Cerdeña y Sicilia debían pasar a España y Nápoles a Saboya ${ }^{34}$.

El día 11 de agosto 1718 los ingleses derrotaron a los españoles en Cabo Passaro. No pudieron evitar que determinadas localidades sicilianas se pronunciaran a favor de España. Finalmente el marqués de Lede y Patiño, en 1720, optaron por la suspensión de armas en la isla y el pragmatismo, al percatarse que no había nada que hacer ante los imperiales y los ingleses, pero sobre todo porque la mitad de los soldados españoles estaban en Inglaterra intentando fomentar un golpe de Estado contra el rey Jorge y restaurar en el trono inglés al pretendiente Jacobo Estuardo. Ambos se lo reprocharon siempre a Alberoni. Patiño, de origen italiano, creía que si no se hubiera movilizado el ejército español se hubiera conseguido su cometido en Italia. La fisura que se produjo entre él y el cardenal fue sangrante e incurable. Por otra parte el vizconde del Puerto que adquirió, a raíz de su defensa de los territorios italianos, el título de marqués de Santa Cruz, el nombramiento de mariscal de campo, teniente general del ejército en las islas y gobernador del castillo de Cagliari no quería abandonar la ciudad y menos entregarla al emperador. La situación fue patética. Se enojó con Patiño como en su momento lo hiciese con Berwick en el sitio de Barcelona. La animadversión llegó a tal punto que Macanaz, años más tarde, llegó a decir que en 1732 el marqués de Santa Cruz fue asesinado en Ceuta por los sicarios de Patiño y su hermano el marqués de Castelar ${ }^{35}$.

Después de Cabo Passaro y antes de la pérdida definitiva de Sicilia, Alberoni intentó conectar con su último recurso, la Santa Sede, y, en concreto, con el cardenal Acquaviva. A través de él pensaba obtener el auxilio del papa y que éste se definiera contra el proceder británico e hiciese reconsiderar a la Cuádruple Alianza. Pero a lo largo de 1718-19 varios factores incidieron en que Clemente XI le negase esta vez su apoyo. En primer lugar, las intrigas del cardenal de Giudice, como antiregalista y ex partidario de la causa austracista. Nunca aceptó que el Santo Padre le otorgara el capelo cardenalicio a su rival en 1717 y jamás olvidó cómo se le despojó de su cargo como inquisidor en España. En segundo lugar, de Giudice se percató de que Felipe V cambió la bula del obispado de Málaga, prevista por el papa para Alberoni, por la del

34. RAH. RousSET, J.: Histoire du Cardinal Alberoni et son ministère ... pp. 268-273.

35. BN. Ms. 2768. MacAnaZ, M. R.: Males, daños perjuicios... pp. 394-395; BNC. Ms.3439. Cuaderno $n^{\circ}$ 33. Manifiesto y cotejo de la conducta que tuvo la majestad de Felipe V contra la del Rey Británico y las razones que al presente Congreso van fulminadas en el tiempo de sus sucesores, p. 42. Aunque el manuscrito no lleva fecha concreta, posiblemente, Macanaz lo escribiera poco después del Congreso de Breda (1748) donde actuó como representante español de Fernando VI para acordar el fin de la Guerra de Sucesión austríaca. El Manifiesto... de Macanaz va acompañado, al igual que el texto de los males, daños y perjuicios..., de narraciones autobiográficas. 
arzobispado de Sevilla en 1718. De Giudice lo denunció y lanzó una ofensiva feroz contra Alberoni ${ }^{36}$.

Macanaz sostuvo que los imperiales influenciaron al papa para que suspendiera, mediante un Breve (4 de junio de 1718), la «gracias de la cruzada lacticinios, subsidio y excusado que están concedidas a SM para estos reinos y las Indias en aquel sexenio» ${ }^{37}$. No quería reconocer la fuerte impregnación antiregalista de la Santa Sede ni entender que la Iglesia quisiese defender su propia parcela ante el regalismo estatal o un proyecto de iglesia nacional.

A lo largo de 1719, Daubenton separó más a Alberoni del rey. Pero no por las razones que argumenta Macanaz de estar «confabulado con el duque de Orleáns» sino porque el confesor real, en su cruzada antijansenista y antiregalista, aprovechó las horas bajas de Alberoni para poder apuntarse un tanto ante el papa y recomendar al rey y a Roma el cese del secretario de la reina ante la fiscalización eclesiástica que aquel pretendía. Acquaviva dejo de escribirle. Por supuesto que Alberoni se había percatado del tema. De hecho intentó sustituir a Daubenton, infructuosamente, por otro jesuita, Francisco de Castro, menos conectado con el oficialismo romano, pero no lo logró. Estuvo durmiendo con su enemigo demasiado tiempo ${ }^{38}$.

La muerte de Clemente XI (1721) y la llegada de Inocencio XIII reforzaron más los postulados de la Compañía de Jesús en Roma, por lo que se abrió un proceso inquisitorial contra Alberoni. Éste se defendió, según cuenta Antonio Valladares (recopilador de la obra de Macanaz), escribiendo en italiano la Apología, alegaciones y memorial donde explicaba a los miembros del tribunal inquisitorial que se habían equivocado de hombre. Alberoni en su defensa alegó que a quién debían controlar era a Macanaz al que responsabilizaba de muchas de las decisiones «tomadas en la corte española en beneficio de la corona y de sus regalías»durante los últimos tiempos ${ }^{39}$.

En el manuscrito Maximas de Alberoni descubiertas se exponen las argumentaciones de la Apología, alegaciones y memorial hechas por el cardenal Alberoni. Allí se defiende ante las acusaciones de la Inquisición romana. Primeramente se justifica alegando que si renunció al arzobispado de Sevilla por el de Málaga era porque el cardenal Paulucci así se lo ordenó en una carta en 1720, por lo que ello no puede considerarse motivo de engaño al papa. En segundo lugar defiende a ultranza que en 1717 fue Clemente XI quién le envió una carta diciéndole que en lugar de enviar la escuadra de mar contra el turco lo hiciera contra Carlos VI, pues así el emperador estaría ocupado y no se preocuparía por la entrada de los españoles en Cerdeña y se podría consumar un

36. BVC. BaCAllar, V.: Comentarios... año 1718, pp. 18-25; RAH. Rousset, J.: Histoire du Cardinal Alberoni et son ministère... pp. 276-278.

37. BN. Ms.2768. MacAnaZ, M. R. de: Males, daños y perjuicios... pp. 145-146.

38. BVC. BaCAllar, V.: Comentarios ..., año 1719, p. 28; BNM. Ms. 2768. MaCAnaz, M. R. de: Males, daños y perjuicios...p. 197.

39. BNC. Ms. 3439. Cuaderno 33. Valladares, A.: Epitome sobre la vida del Sr. Macanaz, pp. 57-64; MAQUedA ABREU, C.: Alberoni: entorno jurídico de un poder singular, Madrid, 2009, pp. 214-224. La autora aporta en esas páginas cartas comentadas sobre la defensa de Alberoni. 
proyecto de unión entre algunos estados italianos estimulados por el papa, el duque de Parma y su sobrina, Isabel, que pensó que las nuevas conquistas podían ser futuros tronos para sus hijos. En esa carta, añade, se podía apreciar como el cardenal Acquaviva y el papa Clemente XI eran cómplices de los reyes españoles. En tercer lugar suscribe que el capelo cardenalicio le fue otorgado por sus propios méritos y no por haber zanjado la operación de la escuadra contra el emperador. Por méritos propios entiende haber expulsado a Macanaz y a la Ursinos de España y, en cambio, haber atraído al nuncio Aldobrandini, en presencia de los reyes para resolver el Ajuste con la Santa Sede tras la ruptura de las relaciones en 1714 .

Contrariamente a las acusaciones mantenidas por el ex inquisidor Francesco del Giudice, Alberoni sostiene cómo él era partidario de restablecerle en su cargo, pero que la reina Farnesio, al constatar como aquél ralentizó la firme del Ajuste con Roma, no quiso saber nada de él. Por último, Alberoni esgrime que hubiera podido defenderse del proceso inquisitorial abierto contra él, si tras su destitución por Felipe $\mathrm{V}$ el 5 de diciembre de 1719, Grimaldo y el confesor Daubenton no le hubieran robado las cartas que guardaba en su poder, altamente comprometedoras, a su paso por Lérida y Gerona, cuando se disponía a salir del país ${ }^{40}$. 